\title{
ANALYSIS OF MULTICAST ROUTING PROTOCOLS FOR HEALTH CARE MONITORING SYSTEM
}

\author{
Joshua Reginald Pullagura ${ }^{1}$, Venkata Rao D ${ }^{2}$ \\ ${ }^{1}$ Vignan's foundation for science Technology and Research Deemed to be University Guntur, India \\ ${ }^{2}$ V.R.Siddhartha Engineering College Vijayawada, India, \\ *1Corresponding author's Email: pjreginald@gmail.com
}

\begin{abstract}
The most important technology we must concentrate on in the different application fields of WSN is health applications and the transmission reliability of health data in multi-hop communication. Short-term health signal failure may be fatal or life-threatening. The topology of an ad hoc network changes regularly due to the node movement and communication in those scenarios depend on the path selected for transfer of information. Since all the nodes are battery-powered, energy-efficient routing should be provided to extend the network's life. In MANET's critical issues include energy usage, QoS (Quality of Services), vulnerability to attacks, and connection stability. Link stability is a topic that needs to be addressed in order to improve communication. Since radio links are generally varied due to node mobility, Link Stability is important to extend the life time. This work gives comparison of three existing multicasting routing protocols that can be used in health monitoring systems. MAODV, LSP-MAODV and PN-SEMRP are compared using NS2 simulation. PN-SEMRP shows better results when compared to the other mechanisms
\end{abstract}

Keywords: AODV, LSP-MAODV, PN-SEMRP, Residual energy, Reliability and Network life time

\section{Introduction}

Mobile ad hoc networks are collections of wireless devices that communicate with each other without using fixed infrastructure. The term "self-configured and self-maintained network" refers to a network that is configured and maintained by itself. Every node in MANET serves as host and a router, allowing it to communicate with other nodes without the need for centralized control. The transmission range and battery power determine how nodes operate in ad hoc networks. Routing operations are performed by each node on the network to allow communication between nodes. If they have enough energy and are beyond the transmission range, all nodes in the network will send their data to their intermediate nodes and they will forward to the next node till the data reaches specified destination. If a mobile node lacks sufficient energy, it cannot transmit data or engage in network operations.

In certain applications nodes are self-managed and can operate in remote locations without the need for maintenance or repair. Typically, data is transferred from source to sink using several hops with low energy consumption, resulting in a lower overall energy cost per packet transmission. As a result, node energy consumption is a critical factor to remember for effective data transmission.

Patients and the elderly who are wearing a bio-shirt with a mobile node attached may be outside of the WSN's restricted contact range. Relay nodes must be deployed appropriately at fixed positions on the ceiling of the indoor environment for data handover in order to ensure quality of biomedical signal transmission through multi-hop contact between mobile node and base station. These relay nodes transmit biomedical signals from a mobile node to gateway through multihop network. Protocols used in health monitoring systems are tabulated below

\begin{tabular}{|l|l|l|l|l|}
\hline $\begin{array}{l}\text { Routin } \\
\text { g } \\
\text { Protoco } \\
\mathbf{l}\end{array}$ & $\begin{array}{l}\text { Size(nod } \\
\text { es) }\end{array}$ & $\begin{array}{l}\text { Topolo } \\
\text { gy }\end{array}$ & $\begin{array}{l}\text { Data } \\
\text { amou } \\
\text { nt }\end{array}$ & $\begin{array}{l}\text { Data } \\
\text { delivery } \\
\text { model }\end{array}$ \\
\hline LEACH & 100 & $\begin{array}{l}\text { Cluster } \\
\text { head }\end{array}$ & Large & $\begin{array}{l}\text { Continuo } \\
\text { us }\end{array}$ \\
\hline $\begin{array}{l}\text { APTEE } \\
\text { N, } \\
\text { GEAR }\end{array}$ & $20-95$ & $\begin{array}{l}\text { Three } \\
\text { Tiered }\end{array}$ & Large & Hybrid \\
\hline MCF & $10-100$ & Star & Large & $\begin{array}{l}\text { Continuo } \\
\text { us }\end{array}$ \\
\hline $\begin{array}{l}\text { PN- } \\
\text { SEMRP }\end{array}$ & $80-100$ & $\begin{array}{l}\text { Cluster } \\
\text { head }\end{array}$ & Large & $\begin{array}{l}\text { Continuo } \\
\text { us }\end{array}$ \\
\hline $\begin{array}{l}\text { MAOD } \\
\text { V }\end{array}$ & 50 & $\begin{array}{l}\text { Rando } \\
\mathrm{m}\end{array}$ & Large & $\begin{array}{l}\text { Continuo } \\
\text { us }\end{array}$ \\
\hline
\end{tabular}

Table 1 Routing protocols used in healthcare

\section{Literature Review}

Many applications are based on Multicasting technology and many protocols are designed to transfer the data from one node to group of nodes. Selection of proper route is important for packet transmission from source to destination nodes. So 
far, the protocols that have been established are either constructive (proactive) or reactive. There are a few Hybrid Protocols being built as well. When opposed to conventional reactive and constructive protocols, Hop Tree based Multicast routing offers better performance. The basic protocols that gained prominence are Multicast Adhoc On-Demand Vector (MAODV), Adhoc Multicast Routing protocol Utilizing Increasing ID Numbers (AMRIS), Core Assisted Mesh Protocol (CAMP), Location Guided Tree (LGT), Lightweight Adaptive Multicast (LAM), and Differential Destination Multicast (DDM).

The Energy Power Aware Routing algorithm is a source routing protocol for on-demand sources that initiates path discovery and uses battery lifetime prediction [1]. The Source node initiates the route discovery process. The transmission or receiving of packets is the primary source of power consumption in network nodes. The network's intermediate nodes lose control as well, since they must forward packets depending on the position of the destination nodes. The route is chosen in the energy power routing protocol based on the node's energy or battery power.

Cluster Based Routing Protocol is a handheld ad hoc network protocol. The protocols separate the mobile nodes of the network into a number of overlying or disjoint 2-hop distance clusters in a distributed manner [3]. A cluster head is chosen from among the clusters to keep track of all of the cluster members' details.

Similarly, [4] justified MAODV is another on-demand protocol in which the route is decided only when a node has something to submit. For tracing the newness of the group situation, each multicast group has a unique address and group sequence numbers.

Another research [8] looked at an ant metaphor in dynamic MANET routing, in which ants disperse the gathered data to the closest sources. Thus, the distributed routing scheme for motor vehicles is defined, which directs them through the city using the shortest time and load account.

Similarly, [9] defined a protocol based on swarm intelligence that employs ants to find routes in multi-hop networks using heuristics. Gavalas [10] described broadcast approach using clustering which increases throughput.

\section{Description of Routing Protocols}

For performance estimation, three multicast research techniques were considered in this paper. The following is a summary of how these approaches operate.

MAODV: Multicast Adhoc on -demand distance vector routing The data packets are multicast using MAODV. By creating the multicast tree, this multicast protocol creates the multicast community. MAODV is the most powerful multicasting protocol for ensuring service quality. The key disadvantages of MAODV, as well as the group's guiding principle, is that it sends several messages even when there is no transmitter, causing delays for the next sender and a considerable amount of controversy in MAODV .

LSPMAODV: Link Stability Based Priority Multicast Adhoc on Demand Routing Protocol

This protocol addresses the limitations of the MAODV multicast routing protocol. The proposed protocol is broken down into several stages, including basic concept formulation, route exploration, route response, and route maintenance. The obtained signal strength is used as a metric to estimate connection and node stability in this protocol. The aim of this protocol is to find a connection (Link) between the nodes that has a high probability of lasting longer. As a threshold, a reliability pair factor $(F$ th $R P)=2.8$ is used. The value of $(F$ th RP) is, in general, application based and set by the system administrator.

PN-SEMRP: Pruning Nodes based stable and Efficient Multicast Routing Protocol

Multicast routing is ensured in this work by creating stable paths to multiple destinations while keeping energy consumption in mind [2]. The modified firefly algorithm is used to choose the cluster head. To reach the destination nodes, multipath route computation is done considering parameters such as energy and security. A Cuckoo-based optimized multilayer feed forward neural network is used to compute the reliability pair factor between neighboring nodes involved in multiple routes, and pruning of neighbor nodes with reliability pair factors less than a threshold is performed.

\section{Results and Discussion}

The parameters used in simulation, are shown in the below table.

\begin{tabular}{|l|l|}
\hline Parameters & Values \\
\hline No of nodes & 80 \\
\hline Network size & $1000 \times 1000 \mathrm{~m}^{2}$ \\
\hline Node placem ent & Random \\
\hline MAC layer Protocol & IEEE 802.11 \\
\hline Sim ulation time & $100 \mathrm{sec}$ \\
\hline Initial energy of node & $100 \mathrm{j}$ \\
\hline RoutingProtocols & $\begin{array}{l}\text { MAODV,LSPMAODV, } \\
\text { PN-SEMRP }\end{array}$ \\
\hline
\end{tabular}

Table 2 Simulation Parameters

\section{Packet delivery ratio}

The ratio data packets successfully transmitted to the total data packets sent is known as the packet delivery ratio. Figure 1 depicts the packet distribution ratio for various node counts. Stable multiple routes are established in PN-SEMRP when compared to other techniques and it controls bandwidth, delay, and energy in multicasting. As a result, PN-SEMRP approach generates a high PDR value 


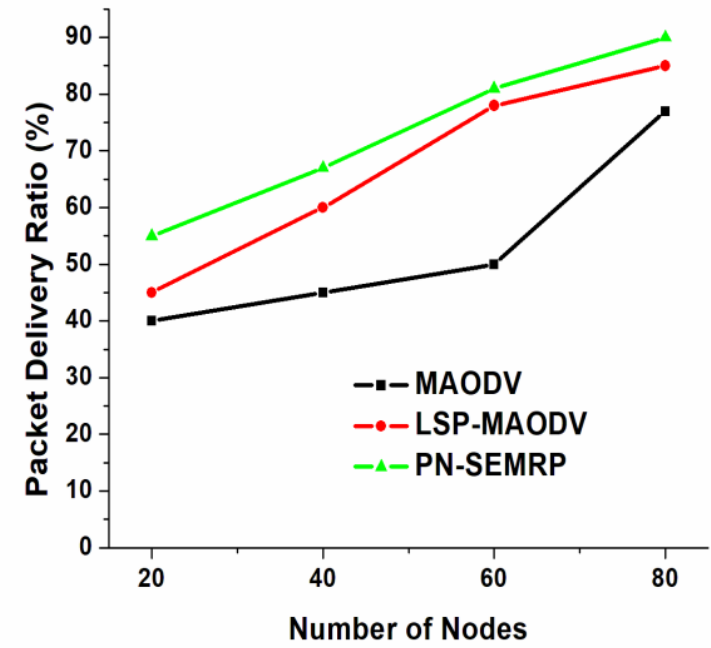

Figure 1 Packet delivery ratio as a function of Nodes

\section{Throughput}

For an efficient protocol Throughput should be high. From Figure 2 it is evident that when number of nodes increased Throughput increases for LSP-MAODV and PN-SEMRP when compared to MAODV protocol. In PN- SEMRP the probability of effective transmission is calculated at each link. Using this computed likelihood, the probability of the entire path from source to destination is calculated. A route probability corresponds to the product of individual probabilities at each link. Hence PN-SEMRP shows higher Throughput when compared two other two mechanisms.

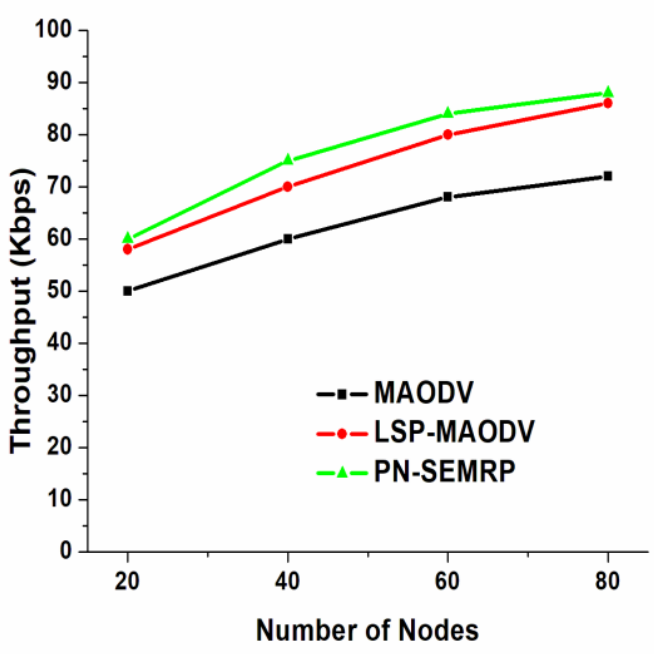

Figure 2 Throughput as a function of Nodes

\section{Delay}

End-to-end delay is the time taken to send data packets from the source to the destination. For better application execution, a low end-to-end delay is desired. Figure 3 depicts the end-to- end delay for various numbers of nodes.PN-SEMRP gives lesser delay due to stable path selected for data transmission and node pruning method incorporated.

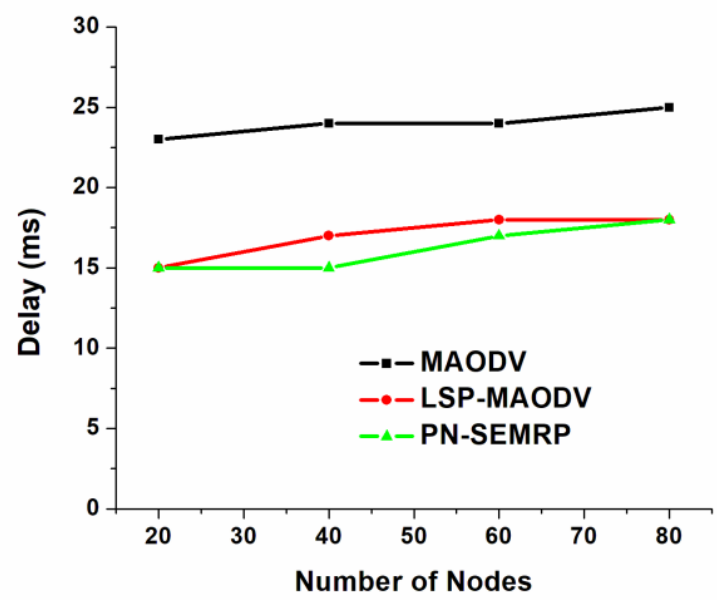

Figure 3 Delay as a function of Nodes

\section{Energy Consumption}

The full amount of energy used by the system's numerous nodes is referred to as the energy consumption. Figure 4 depicts the energy consumption for various node counts. It is obvious that the proposed solution uses less energy than other protocols.PN-SEMRP consumes lesser energy when compared to other two mechanisms.

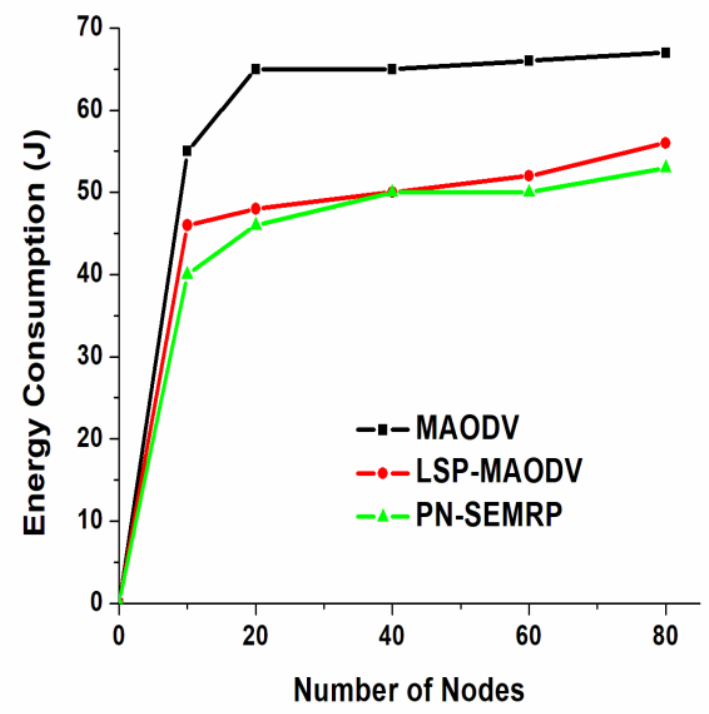

Figure 4 Energy consumption versus No of Nodes

\section{Conclusion}

Many routing protocols have been developed and used in a variety of wireless sensor network applications, including environmental, health and location monitoring. The simulation results in this paper show that PN-SEMRP outperforms the other two protocols due to the use of secure, 
stable paths and a keying mechanism. In terms of throughput, PDR, delay, and energy consumption, simulation results show that PN-SEMRP outperforms the existing MAODV and LSPMAODV multicast routing protocols.

\section{References}

[1] Shivashankar, Hosahalli, Narayanagowda Suresh, Golla Varaprasad and Guruswamy jayanthi "Designing Energy Routing Protocol with Power Consumption Optimization in Manet" IEEE Transactions on emerging topics in computing VOL 2 ,NO 2, June 2014

[2] Joshua Reginald Pullagura , D Venkata Rao "Pruning Nodes based Stable and Efficient Multicast Routing Protocol in Manet" Journal of Adv Research in Dynamical \& Control Systems, Vol. 11, No. 12, 2019.

[3] M.Vijayalakshmi, Dr D Sreenivasa Rao "Cluster based Multicast Adhoc on Demand Routing protocol for increasing link stability in Manets" Global Journal of Computer science and Technology(E) Vol XVII Issue 11, 2017.

[4] Royer, E.M and Chai-Keong Toh. "A Review of Current Routing Protocols for Ad Hoc Mobile Wireless" Networks. IEEE Personal Communications, pp. 46-55, April 1999.

[5] Joshua Reginald Pullagura, D.Venkata Rao “ Simulation based performance evaluation of energy efficient protocols in ad hoc networks", Journal of Advanced Research in Dynamical and Control Systems, Special Issue - 02 / 2017, volume 9,pp 1141-1149.

[6] J. Wu and J. Cao, "Connected k-hop clustering in ad hoc networks," in ICPP "05: Proc. of the 2005 International Conference on Parallel Processing (ICPP ${ }^{\text {ee }}$ 5). Washington, DC, USA: IEEE Computer Society, 2005, pp. 373-380.

[7] Wang, Y., Chen, R., Cho, J. H., Swami, A., \& Chan, K. S. (2015). Trust-based service composition and binding with multiple objective optimization in service-oriented mobile ad hoc networks. IEEE Transactions on Services Computing, 10(4), 660672.

[8] R. Agarwal, M. Matwani, "Survey of Clustering Algorithms for MANET", International Journal on Computer Science and Engineering, Vol. 1(2), 2009, pp. 98-104.

[9] Dorigo, M. Birattani and Y. Steeutzle, "Ant Colony Optimisation- Artificial Ants as a Computational Intelligence Technique", IEEE Computational Intelligence Magazine, Nov 2006, pp28-39.

[10] Gavalas, D., G. Pantziou, C.Konstantopoulos, and B.Mamalis, 2006. "Clustering of Mobile Ad Hoc
Networks: An Adaptive Broadcast Period Approach”. IEEE ICC, 9:4034-4039. 